\title{
Clareza na utilização dos sistemas sociais da teoria de alcance de metas*
}

\author{
CLARITY IN THE USE OF THE SOCIAL SYSTEMS FROM THE THEORY OF GOAL ATTAINMENT \\ CLAREZA DE LA UTILIZACIÓN DE LOS SISTEMAS SOCIALES DE \\ LATEORÍA DE ALCANCE DE METAS
}

\section{Emilia Soares Chaves', Thelma Leite de Araujo", Marcos Venícius de Oliveira Lopes"I}

\footnotetext{
Estudo realizado na disciplina "Análise Crítica das Teorias de Enfermagem", Programa de PósGraduação em Enfermagem, Universidade Federal do Ceará (UFC)

I Enfermeira. Doutoranda da Universidade Federal do Ceará. Bolsista CAPES. Professora Substituta do Departamento de Enfermagem, Universidade Federal do Ceará (UFC) Fortaleza, CE, Brasil. emilliasoareschaves@ yahoo.com.br

II Enfermeira. Doutora. Professora Adjunta do Departamento de Enfermagem, Universidade Federal do Ceará (UFC) Fortaleza, CE, Brasil. Pesquisadora do CNPq. thelma@ufc.br

III Enfermeiro. Doutor Professor Adjunto do Departamento de Enfermagem, Universidade Federal do Ceará (UFC),

Fortaleza, CE, Brasil. Pesquisador do CNPq.

marcos@ufc.br
}

\section{RESUMO}

Objetivou-se verificar a clareza na organização dos sistemas sociais da Teoria de Alcance de Metas. Estudo teórico-reflexivo, tendo como referencial para análise um Modelo de Análise de Teorias. Desenvolvido nos meses de abril, maio e junho de 2005 , sendo analisadas uma Dissertação e duas Teses. Quanto à definição operacional dos conceitos, as três pesquisas definiram adequadamente os conceitos que o Modelo Conceitual aponta. Em relação à validade de conteúdo e construto, foram identificadas lacunas. Em um estudo, por exemplo, os grupos de trabalho nos quais os indivíduos estavam inseridos não foram condizentes com o conceito de sistema social apresentado pela Teoria. Dessa forma, os estudos necessitam ainda de atenção quanto à utilização de conceitos apresentados em teorias ou em modelos teóricos.

\section{DESCRITORES}

Teoria de enfermagem. Modelos de enfermagem. Estudo de validação.

\section{ABSTRACT}

This study was aimed at verifying the clarity in the organization of the social systems in the Theory of Goal Attainment. It is a theoretical-reflexive study that uses as referential for analysis a Model of Analysis of Theories. One thesis and two dissertations were analyzed in the months of April, May and June of 2005. Regarding the operational definition of the concepts, all three defined adequately the concepts pointed out in the Conceptual Model, making use of them in the situations of the studies. In what refers to the validity of content and construct there were gaps identified. In one of the studies, for example, the work groups to which the individuals belonged were not consonant with the Theory's social system concept. Thus the studies still require attention as to the use they make of concepts presented in theories or in theoretical models.

\section{KEY WORDS}

Nursing theory.

Models nursing.

Validation studies.

\section{RESUMEN}

Tuvo como objetivo verificar la clareza en la organización de los sistemas sociales de la Teoría de Alcance de Metas. Estudio teórico-reflexivo, teniendo como referencial para análisis un Modelo de Análisis de Teorías. Desarrollado en los meses de abril, mayo y junio de 2005, siendo analizadas una Disertación y dos Tesis. Cuanto a la definición operacional de los conceptos, las tres pesquisas definieron adecuadamente los conceptos que el Modelo Conceptual apunta. En relación a la validad de contenido y construcción, fueron identificadas lagunas. En un estudio, por ejemplo, los grupos de trabajo en los cuales los individuos estaban inseridos no fueron condimentes con el concepto de sistema social por la Teoría. De esa forma, los estudios necesitan aún de atención cuanto a la utilización de conceptos presentados en teorías o en modelos teóricos.

\section{DESCRIPTORES}

Teoría de enfermería.

Modelos de enfermería. Estudios de validación. 


\section{INTRODUÇÃO}

Uma teoria de enfermagem pode ser definida como uma conceitualização de algum aspecto da realidade de enfermagem que tem como objetivo descrever o fenômeno, explicar as relações entre estes e predizer conseqüências ou prescrever o cuidado de enfermagem ${ }^{(1)}$. As teorias, na enfermagem, se constroem a partir da idealização de uma prática, visando aperfeiçoar a assistência. Existem várias e cada uma delas possui uma forma particular de identificar um fenômeno da profissão.

A incorporação de teorias na prática profissional, por parte dos enfermeiros, ainda é incipiente. A dificuldade em compreender os elementos e a estrutura de uma teoria de enfermagem pode ser um dos motivos para isto. Um modo de minimizar este fato, podendo levar os profissionais a escolherem teorias de enfermagem mais adequadas a determinadas realidades ou situações específicas, é a utilização de modelos para analisá-las.

A análise de teorias é definida como um processo de identificação de partes e componentes que são examinados em relação ao número de critérios identificados, incluindo a análise de conceito e de teoria ${ }^{(1)}$.

O desenvolvimento e a avaliação de teorias são processos cíclicos, contínuos, dinâmicos e dependentes. A avaliação existe para ser aplicada na prática profissional, no desenvolvimento dos currículos, no ensino, na operaciona-lização de qual teoria possa ser utilizada na pesquisa ou nas tomadas diárias de decisão. Além disso, dentre os diversos benefícios da análise de teorias, tem-se: serve para decidir qual teoria é mais apropriada a ser utilizada como referencial para pesquisa, ensino, administração ou consultoria; comparar e contrastar diferentes explicações para o mesmo fenômeno; identificar teorias eficazes para explorar algum aspecto da prática ou para guiar um projeto de pesquisa; promover o potencial de mudanças construtivas e no maior desenvolvimento da teoria; identificar as escolas de pensamento de uma disciplina; promover mudanças na prática clínica, definir prioridades e identificar conteúdo para o ensino e guias para a administração de enfermagem; ter refe-renciais de enfermagem para justificar a profissão para o público; identificar estratégias para o desenvolvimento da teoria; definir o domínio de uma disciplina $^{(1)}$.

Vale ressaltar que a finalidade da avaliação de uma teoria não é somente sua validação. Também é importante considerar o fundamento e a afirmação das suas partes, assim como dos componentes da mesma. Embora não seja possível tecer generalizações sobre uma teoria, sobre a situação de saúde e doença dos indivíduos, ela é muito útil para o entendimento da experiência de vivenciar a saúde e a doença, em especial para as ciências que lidam com a experiência humana e com o processo orientado para a prática.

Com base nisto, buscamos desenvolver uma avaliação do aspecto crítico da Teoria de Alcance de Metas de Imógene King tendo como base um modelo de análise ${ }^{(1)}$.

A crítica da teoria é definida como o exame crítico ou estimativa de uma coisa ou situação com a visão de determinar sua natureza e limitações ou sua conformidade aos padrões. Vários critérios são essenciais à crítica da teoria. Estes têm relações entre estrutura e função, diagrama da teoria, círculo de contágio, utilidade e componentes externos. A crítica considera a relação entre estrutura e função. Isto é realizado ao fazer uma avaliação crítica e julgamento das relações entre os diferentes componentes da teoria, tais como: pressupostos, conceitos, proposições e domínio. Além disso, alguns critérios podem ser considerados, tais como clareza, consistência, simplicidade/complexidade e tautologia/teleologia ${ }^{(1)}$.

A avaliação objetiva e a crítica à teoria são processos tão complexos quanto subjetivos. Para simplificar qualquer avaliação devemos dividi-la em componentes. Por isto, dentro do aspecto da crítica da teoria, abordaremos mais especificamente o quesito clareza.

Clareza é definida como um continum variando de alta a baixa. Ela denota a precisão de limites, uma comunicação do senso de ordenação e vividez dos significados, e consistência através da teoria. A clareza é demonstrada em pressupostos, conceitos e proposições bem como em conceitos de domínio. Para se obter a clareza nos conceitos deve-se ter definições teóricas e operacio-nais que sejam consistentes através da teoria e, que são apresentados em formato parcimonioso, e consistentes com os pressupostos e proposições da teoria ${ }^{(1)}$.

O modelo de avaliação proposto ${ }^{(1)}$ pode ser utilizado em partes ou na teoria como um todo. $\mathrm{O}$ avaliador pode escolher enfocar qualquer uma das etapas (descrição, análise, crítica ou verificação) ou então qualquer um de seus componentes. Uma análise cuidadosa da teorista e de suas contribuições é tão valiosa para o avanço do conhecimento quanto a verificação de uma proposição da teoria. Verificações focalizadas na aceitação ou rejeição de proposições ou na geração de proposições ajudam a explicar, descrever e predizer o conteúdo substantivo do campo.

Atualmente, existe um grande número de teorias de Enfermagem, utilizadas em situações diversas. A escolha, neste estudo, para a análise de uma teoria específica - Teoria de Alcance de Metas, partiu da realização de um trabalho anterior, no qual tivemos um contato inicial com a mesma. 
A partir de então, a necessidade de conhecimento mais profundo e reflexivo tornou-se crescente.

Percebeu-se, no entanto, que esta teoria englobava alguns aspectos complexos e uma diversidade de conceitos. Este conhecimento traz valiosa contribuição em relação às reflexões realizadas e possibilitar novas alternativas para a prática, portanto, o presente estudo tem como objetivo verificar a unidade de análise clareza na organização dos sistemas sociais da Teoria de Alcance de Metas de Imógene King.

\section{MÉTODO}

Estudo classificado como teórico-reflexivo. Foi desenvolvido durante os meses de abril, maio e junho de 2005. Foram analisadas uma dissertação de Mestrado e duas teses de Doutorado. Os trabalhos utilizaram como base a Teoria de Alcance de $\operatorname{Metas}^{(2)}$. A dissertação e uma das teses abordaram a adesão ao tratamento da hipertensão arterial $^{(3-4)}$. O outro trabalho de conclusão de Doutorado enfocou a gravidez na adolescência ${ }^{(5)}$.

Para análise dos dados foi utilizado o Modelo de Análise de Meleis, mais especificamente o aspecto que se refere à crítica à teoria enfatizando a unidade de análise clareza ${ }^{(1)}$. Dentro do material analisado (dissertação e teses), foi investigada a aplicação dos sistemas sociais como parte da estrutura dinâmica de sistemas abertos.

Os procedimentos adotados para o desenvolvimento do estudo incluíram:

- $1^{\text {a }}$ etapa: leitura da teoria, buscando identificar o conceito de sistema social, seus pressupostos, proposições e conceitos relacionados.

- $2^{\mathrm{a}}$ etapa: descrição dos componentes do sistema social apresentado na teoria - clareza do conceito.

- $3^{\mathrm{a}}$ etapa: leitura e análise da dissertação e das duas teses.

-4 $4^{a}$ etapa: análise da congruência do conceito sistema social nos três estudos.

\section{RESULTADOS}

\section{Teoria de Alcance de Metas}

A teoria em apreço tem como foco central o alcance de metas para o cuidado de seres humanos, sendo estas metas estabelecidas de comum acordo entre enfermeiro e paciente. Como toda teoria, apresenta pressupostos, proposições e conceitos chaves para o seu desenvolvimento (Quadro 1).

Quadro 1 - Componentes da teoria

\begin{tabular}{|c|c|c|}
\hline \multicolumn{3}{|c|}{ COMPONENTES DA TEORIA } \\
\hline Pressupostos & Proposições & Conceitos envolvidos \\
\hline $\begin{array}{l}\text { Enfermagem é percepção, pensamento, } \\
\text { relacionamento, julgamento e ação lado } \\
\text { a lado com o comportamento de } \\
\text { indivíduos que vêm a uma situação de } \\
\text { enfermagem. }\end{array}$ & $\begin{array}{l}\text { A meta da enfermagem é ajudar o } \\
\text { indivíduo a manter sua saúde para que ele } \\
\text { possa desempenhar bem seus papéis. }\end{array}$ & Interação \\
\hline $\begin{array}{l}\text { Saúde é um processo de crescimento } \\
\text { humano e desenvolvimento que nem } \\
\text { sempre são regulares e sem conflito. }\end{array}$ & $\begin{array}{l}\text { Os enfermeiros, em interação com os } \\
\text { clientes, estabelecem metas, exploram e } \\
\text { concordam com os meios para alcançá-los. }\end{array}$ & Percepção \\
\hline $\begin{array}{l}\text { Cada ser humano percebe o mundo } \\
\text { como uma pessoa total que interage } \\
\text { com outros indivíduos ambiente. }\end{array}$ & $\begin{array}{l}\text { A efetividade do cuidado pode ser medida } \\
\text { por meio da obtenção ou não das metas } \\
\text { para promoção ou manutenção da saúde e } \\
\text { recuperação da enfermidade. }\end{array}$ & Comunicação \\
\hline $\begin{array}{lccr}\text { Os seres } & \text { humanos } & \text { são } & \text { considerados } \\
\text { sistemas } & \text { abertos } & \text { em } & \text { constante } \\
\text { interação. } & & & \\
\end{array}$ & & Ego \\
\hline $\begin{array}{l}\text { O foco da enfermagem é o cuidado de } \\
\text { seres humanos. }\end{array}$ & & Papel \\
\hline & & Crescimento e desenvolvim ento \\
\hline & & Tempo e espaço \\
\hline
\end{tabular}

A enfermagem é conceituada como percepção, pensamento, relacionamento e ação ${ }^{(2)}$. A autora enfatiza que o ser humano percebe o mundo como uma pessoa total fazendo transações com os indivíduos e coisas no ambiente.

A Teoria descreve a natureza de interações enfermeiracliente que conduzem à realização de metas, as quais dão base para avaliação da efetividade do cuidado, por meio do alcance ou não destas metas para promoção da saúde, ma- nutenção da saúde ou recuperação da enfermidade. Considerando que os seres humanos são sistemas abertos, pois interagem com o ambiente, uma organização destes sistemas em uma estrutura dinâmica foi proposta. Os indivíduos são chamados sistemas pessoais. Os indivíduos formam grupos e esta formação cria outro tipo de experiência humana dentro dos sistemas interpessoais. Alguns destes grupos com interesses comuns criam outro tipo de experiência humana dentro de uma comunidade ou sociedade chamados sistemas sociais, conforme apresentado na Figura $1^{(2)}$. 


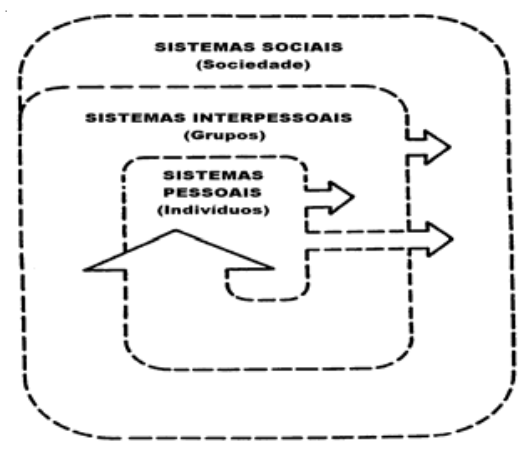

Figura 1 - Sistemas sociais
Dentro de uma sociedade, grupos de referência tendem a influenciar percepções, julgamentos e comportamentos de indivíduos. Assim, o sistema social é definido como um sistema de limite organizado de papéis sociais, comportamentos e práticas desenvolvidas para manutenção de valores e de mecanismos para regular práticas e papéis ${ }^{(2)}$. Envolvem alguns conceitos e possuem algumas características estruturais e funcionais. Fazem parte dos sistemas sociais os grupos familiares, religiosos, educacionais e de trabalho (Quadro 2).

Quadro 2 - Sistemas sociais

\begin{tabular}{|l|l|}
\hline \multicolumn{2}{|c|}{ SISTEMAS SOCIAIS } \\
\hline Organização & Componentes (Características estruturais e funcionais) \\
\hline Autoridade & Valores \\
\hline Poder & Padrões de comportamento \\
\hline Status & Papéis prescritos \\
\hline Tomada de decisão & Status \\
\hline & Autoridade \\
\hline
\end{tabular}

A análise de como estes aspectos encontram-se em trabalhos que tiveram como suporte a Teoria de Alcance de Metas $^{(2)}$, faz-se importante por desvelar em quais realidades ou situações ela pode ser adequadamente utilizada. Além disso, é importante o questionamento sobre a utilização de teorias de forma clara e congruente.

\section{Apresentação dos trabalhos}

Para melhor compreensão deste estudo, faz-se necessária uma apresentação sumária dos trabalhos submetidos à nossa avaliação. Como mencionado anteriormente, tratamse de três produções: duas teses e uma dissertação ${ }^{(3-5)}$.

A autora da dissertação ${ }^{(3)}$ abordou a falta de adesão ao tratamento da hipertensão arterial com o objetivo de descrever as respostas dos pacientes com hipertensão não aderentes ao tratamento, relacionando-as aos sistemas pessoal, interpessoal e social do Modelo Conceitual de King. Teve como amostra uma clientela de um programa de controle de um Centro de tratamento de hipertensão e diabetes, mas que apresentavam somente a hipertensão arterial como problema de saúde. Os achados foram tratados utilizando o método de análise de conteúdo(6).

Em um segundo momento, ao realizar sua tese de Doutorado, a mesma autora objetivou desenvolver e avaliar uma tecnologia de cuidado ao paciente com dificuldade de adesão ao tratamento da hipertensão arterial a partir dos pressupostos de King, favorecendo a participação individual, interpessoal e familiar no cuidado ${ }^{(2,4)}$. Este estudo, que teve uma abordagem de pesquisa convergente assistencial, foi desenvolvido em uma Unidade Básica de Saúde da Família com 22 pacientes com dificuldades de seguimento terapêutico. O acompanhamento dos pacientes foi realizado por meio de consultas de enfermagem, reuniões em grupo, visitas domiciliares, observação participante e aplicação de instrumento de avaliação de adesão.

Na segunda tese $\mathrm{e}^{(5)}$ foi realizado um estudo de caso com o objetivo de estabelecer um perfil diagnóstico das respostas de adolescentes à sobreposição de crises vitais determinada pela ocorrência simultânea da adolescência e da gravidez pré-conjugal. Utilizou-se como marco teórico a estrutura conceitual de Imógene King. A amostra do estudo constituiu-se de treze adolescentes grávidas solteiras atendidas, para assistência pré-natal, em uma unidade de saúde do município de Ribeirão Preto - SP.

\section{Análise dos trabalhos}

Dentro do contexto de cada um dos trabalhos apresentados, buscou-se especificamente a clareza na aplicação do conceito de sistema social de King às situações escolhidas, envolvendo, por sua vez, os demais conceitos e seus componentes. Para alcançar este objetivo, buscamos responder às questões colocadas pelo autor ${ }^{(1)}$ : os conceitos são operacionalmente definidos? Eles parecem ter validade de conteúdo e construto? As respostas possibilitarão determinar a clareza do conceito na teoria e nos trabalhos analisados.

O conceito de sistema social proposto por King deve ser analisado de forma crítica e reflexiva a fim de que possa ser bem delineado e utilizado coerentemente a partir do conteúdo da teoria. Ao se comparar a disposição dos indivíduos dentro dos sistemas interpessoais e sociais, surgem dúvidas: para a formação dos primeiros, os indivíduos interagem 
em díades, tríades e grupos pequenos e grandes; para formar o segundo, os grupos têm interesses especiais, sendo a família considerada um destes; a família, porém, não pode ser tida apenas como um grupo pequeno no qual os indivíduos estão interagindo, sem necessariamente terem metas comuns? Assim, não poderia ser considerada como sistema interpessoal ao invés de social? Que critérios teriam levado a autora da teoria a classificá-la dessa forma? Bem como, o agrupamento em tríade (sistema interpessoal) não poderia apresentar interesses comuns, sendo desta maneira considerado como sistema social? Ao nosso ver estas questões não nos parecem bem definidas, podendo dificultar sua aplicação.

Sabe-se que muitas transformações ocorreram desde que King escreveu seu Modelo Conceitual. A própria família sofreu grandes mudanças no seu perfil; a imposição financeira provocou mudanças nas relações e interações entre os indivíduos. Mas como a base do seu Modelo são os Sistemas Abertos, a família poderia exibir características tanto dos sistemas interpessoais como dos sistemas sociais. É ressaltada que a separação feita por King entre os três sistemas de sua estrutura conceitual - pessoal, interpessoal e social - é artificial, cumprindo a função prática de facilitar sua descrição ${ }^{(5)}$. É considerado, ainda, que os conceitos selecionados por King são fundamentais para o entendimento de cada sistema e seus relacionamentos, sendo dispostos nos três sistemas de modo um tanto arbitrário, e cita a autora:

os conceitos na estrutura não estão limitados a apenas um dos sistemas dinâmicos interatuantes, mas transitam nos três sistemas ${ }^{(7)}$.

Verificamos que os três estudos avaliados trouxeram em seus contextos o sistema social como um dos determinantes para a condução dos trabalhos.

Um das autoras ${ }^{(3)}$, estabeleceu categorias, encontradas na análise do comportamento de não-adesão dos participantes do estudo, que segundo a pesquisadora, estavam relacionadas aos sistemas sociais. Foram estas: grupos dos quais participa (no trabalho, na comunidade, na igreja) associada ao conceito de organização, relações críticas (autoritarismo familiar, autoritarismo do profissional) - autoridade, interferência dos relacionamentos (no trabalho, na aquisição de remédios, na doação de poder a outrem) - relação de poder, pessoas influentes (na família, entre amigos) status e tomando decisões em relação aos problemas cotidianos (enfrentamento, isolamento) - tomada de decisão.

Quanto aos grupos em que participavam no trabalho, o estudo se refere mais como uma relação de cooperação entre colegas, e não como uma formação de grupos ou organizações dentro das instituições. Isto vai ao encontro do modelo que coloca como organização: unidade social caracterizada por estrutura, funções e recursos para alcançar metas $^{(2)}$. Quando se refere a grupos na comunidade, o faz no sentido de os sujeitos do estudo não participarem de atividades da comunidade e somente relatarem interações com vizinhos.

No contexto do autoritarismo familiar e do profissional, o conceito de autoridade mostrou estreita relação com o conceito de poder. Isto é mesmo demonstrado dentro do Modelo Conceitual quando se apresenta ser autoridade o poder para tomar decisões que guiam ações de si e dos outros; e poder está relacionado com autoridade, sendo um processo por meio do qual uma ou mais pessoas influenciam outras em uma situação ${ }^{(2)}$. Como referido pela autora do trabalho, a autoridade foi destacada pelo membro familiar com maior poder aquisitivo ou pelo profissional de saúde, detentor de um conhecimento superior.

O conceito de status esteve relacionado, no estudo, a pessoas percebidas como influentes tanto dentro da família como entre amigos, que tinham como fornecer alguma ajuda àqueles indivíduos. Isto corrobora com o referido por King, para quem status é a posição de um indivíduo em um grupo, percebido por outros indivíduos também do grupo; é o prestígio adquirido em um papel ${ }^{(2)}$.

Tomada de decisão é definida como um processo dinâmico e sistemático pelo qual são escolhidas alternativas por indivíduos ou grupos para atingir uma meta ${ }^{(2)}$. Os participantes do estudo em questão demonstraram a aplicação deste conceito. As decisões tomadas foram apresentadas em forma de isolamento, retraimento, ou em forma de enfrentamento (orar, andar ou conversar).

No estudo ${ }^{(4)}$ foram descritas a história de vida/doenças de cada participante e a partir delas foram extraídos os aspectos inclusos em cada sistema e formulados diagnósticos de enfermagem referentes aos sistemas. Para a identificação dos dados em relação aos sistemas pessoal, interpessoal e social, inclusos dentro do histórico, foi formulado um guia de preenchimento do roteiro da consulta de enfermagem. Com relação ao sistema social, o histórico de enfermagem contemplou: percepção/acompanhamento geral da saúde - investigando qual a percepção de saúde na comunidade; nutrição e metabolismo - investigando se alguém na família tinha alterações de saúde relacionadas a este aspecto; eliminações - perguntando se tinha cômodos na casa destinados a este fim, se era acessível; cognição e percepção - observar/perguntar se a família o isola e perguntar o que está havendo. Para a investigação dos aspectos de exercícios e atividades, cognição e percepção, sono e repouso, autoconceito, papéis e relacionamentos, sexualidade e reprodução, estresse, crenças e valores, medos e inseguranças, o sistema social não foi incluído. Os conceitos de organização, autoridade, poder, status e tomada de decisão foram percebidos somente a partir da observação participante. 
Os sistemas interpessoal e social foram descritos no texto de forma conjunta como se não ficassem claras suas distinções. Como a pesquisadora trabalha com as famílias destes pacientes, retomam-se as indagações feitas anteriormente referentes a estes dois sistemas. É justamente quando se aborda a família que a referência a estes dois sistemas se confundem dentro do estudo. Família e amigos na comunidade aparecem como suportes sociais para estes pacientes.

No estudo ${ }^{(5)}$, cujo foco foram adolescentes grávidas solteiras, os pressupostos e conceitos da Teoria de Imógene King estiveram presentes em todas as etapas. Abordou-se alguns aspectos do processo de socialização da mulher relacionados ao modo como as adolescentes respondiam, no âmbito pessoal, interpessoal e social, à gestação pré-conjugal. Os dados foram apresentados a partir de uma visão de conjunto, em que se buscou descrever quem eram as adolescentes grávidas solteiras do estudo; onde elas se situavam e como percebiam o meio ambiente sócio-familiar; quais as suas respostas humanas à sobreposição de crises vitais que vivenciavam; e como essas respostas se caracterizavam em termos de evidências (subjetivas e/ou objetivas) pessoais, interpessoais e sociais, e os possíveis fatores a elas relacionados.

Alguns conceitos referentes ao sistema social foram trazidos na parte introdutória do estudo de forma clara, como pode ser percebido na passagem:

A menarca, por exemplo, não pode ser vista como um simples fato biológico natural, mas como um fenômeno que se destaca por suas dimensões socioculturais, ou seja, que implica uma redefinição de status para a menina, agora socialmente transformada em moça, e a observância de novos papéis, atitudes e comportamentos correspondentes a esse novo status, os quais variam em diferentes contextos históricos, culturais ou sociais ${ }^{(5)}$.

O instrumento de coleta de dados utilizado com as adolescentes foi composto por três partes (sistema pessoal, interpessoal/social, encontros subseqüentes), e fundamentado na Teoria de Alcance de Metas. Os dados relativos ao sistema interpessoal/social contemplaram: questões relativas à constituição da família e posição da adolescente no quadro familiar; distribuição de atividades na família; participação da família na comunidade em que a adolescente estava inserida; percepção da adolescente sobre o exercício da autoridade e poder na família; pessoa(s) que mais exerce(m) influência sobre a adolescente e participação dessa(s) pessoa(s) no seu processo de tomada de decisões relativos à gravidez; padrão de comunicação e interação familiar; percepção e desempenho de papéis; padrão usual de resposta da adolescente a situações problemáticas/estressantes; relacionamento interpessoal da adolescente com o parceiro sexual, com os familiares ou outras pessoas significativas; avaliação de mudanças que a gestação pré-conjugal possa ter provocado nesses relacionamentos. Mais uma vez, como no estudo anterior, sistema interpessoal e social encontramse estreitamente relacionados.

Para o sistema social, a autora refere que o conceito básico selecionado foi organização, conceito esse descrito por King como um sistema que exibe padrões de comportamento individual e grupal, padrões de comunicação e padrões de interação que estão ligados aos subconceitos de autoridade, poder, status e tomada de decisão. No entanto, para todas as questões do instrumento, foram feitos paralelos entre as respostas das adolescentes com os conceitos fornecidos pela Teoria, mostrando a nosso ver, que todos os conceitos foram tomados como base para embasar os dados do estudo.

No texto, a autora também afirma que tanto autoridade quanto poder são conceitos concebidos no contexto das relações interpessoais que se estabelecem em organizações sociais, de que a família é um exemplo. Porém, para King, estes conceitos não estão referidos nos sistemas inter-pessoais diretamente, mas sim nos sistemas sociais. Na nossa concepção, mais uma vez os aspectos dos sistemas sociais e interpessoacis se confundem e causam ambigüidades.

A pesquisadora aplicou na prática a estrutura teórica de Imogene King, procurando demonstrar a inter-relação e interdependência que ocorre entre os aspectos psicobiológicos, psicoemocionais e psicossociais, que caracterizam o modo particular como os seres humanos respondem aos eventos vitais; que caracterizam, portanto, o modo como se configuram as respostas humanas das adolescentes solteiras à gravidez.

\section{CONSIDERAÇÕES FINAIS}

A análise crítica é fundamental para o desenvolvimento de uma teoria, e deve ser parte de nossa responsabilidade como clínico, acadêmico e administrador. Cabe a cada um de nós a segurança e o conhecimento para direcionar a pesquisa e a prática, visando melhorá-los.

Assim como referem outros autores ${ }^{(8-9)}$, a utilização de teorias possibilita a observação da prática de enfermagem. São diversas as teorias existentes. Os pesquisadores e profissionais devem escolher àquelas que mais se adequam à situação vivenciada e procurar conhecê-las e adotar seus conceitos com a maior clareza possível. A Teoria de Alcance de Metas pode ter aplicação em muitos contextos, como os apresentados nos estudos analisados - indivíduos com doenças crônicas e em situações que possam prejudicar o bem estar (gravidez na adolescência). Seja qual for a situação, é importante oferecer um atendimento humanizado, no qual muitas vezes, a família tem seu papel. Nos três trabalhos apresentados, o contexto familiar foi destacado, mostrando sua importância para os indivíduos. 
Retomando o objetivo deste estudo de buscar a clareza na aplicação do conceito de sistema social da Teoria de King às situações escolhidas, resta saber se as respostas às questões colocadas ${ }^{(1)}$ foram positivas ou não. No que se refere à definição operacional dos conceitos, pode-se afirmar que as três pesquisas analisadas definiram adequadamente os conceitos que a Teoria de King aponta, fazendo uso destes conceitos nas situações do estudo.

Quanto à validade de conteúdo e construto, foram identificadas lacunas. No estudo relacionado com a adesão ao tratamento da hipertensão ${ }^{(3)}$, por exemplo, os grupos de trabalho nos quais os indivíduos estavam inseridos não foram condizentes com o conceito de sistema social apresentado por King. Também quando a autora se refere aos grupos na

\section{REFERÊNCIAS}

1. Meleis AI. Theoretical nursing: development and progress. $3^{\text {rd }}$ ed. Philadelphia: Lippincont; 1997.

2. King IM. A theory for nursing: systems, concepts, process. New York: Wiley; 1981.

3. Moreira TMM. Descrevendo a não adesão ao tratamento a partir de uma compreensão de sistemas [dissertação]. Fortaleza: Departamento de Enfermagem, Faculdade de Farmácia, Odontologia e Enfermagem, Universidade Federal do Ceará; 1999.

4. Moreira TMM. Tecnologia do cuidado na busca da adesão ao tratamento da hipertensão arterial: desenvolvimento e avaliação de uma experiência em Fortaleza-Ceará [tese]. Fortaleza: Departamento de Enfermagem, Faculdade de Farmácia, Odontologia e Enfermagem, Universidade Federal do Ceará; 2003.

5. Garcia TR. Cuidando de adolescentes grávidas solteiras [tese]. Ribeirão Preto: Escola de Enfermagem de Ribeirão Preto, Universidade de São Paulo; 1996. comunidade, coloca a categoria, mas não havia participantes fazendo parte da mesma. No estudo ${ }^{(4)}$, indagar sobre a existência de cômodos no domicílio não nos pareceu ter relação direta com os sistemas sociais, principalmente em relação à família que foi o ponto de apoio para o estudo. $\mathrm{O}$ estudo $^{(5)}$ mostrou-se o mais congruente com o conceito de sistema social.

A partir destes aspectos expostos, pode-se chegar a conclusão de que, os estudos necessitam ainda de atenção quanto à utilização de conceitos apresentados em teorias ou em modelos teóricos, sobretudo para que critérios como a clareza não fiquem prejudicados, dificultando o entendimento dos leitores e a compreensão da forma pela qual a teoria pode contribuir para a prática profissional.

6. Bardin L. Análise de conteúdo. Lisboa: Edições 70; 1977.

7. King IM. A systems framework for nursing. In: Frey MA, Sieloff CL, editors. Advancing King's systems framework and theory of nursing. Thousand Oaks: Sage; 1995. p. 14-22.

8. Oliveira MMC, Almeida CB, Araujo TL, Galvão MTG. Aplicação do processo de relação interpessoal de Travelbee com mãe de recém-nascido internado em uma unidade neonatal. Rev Esc Enferm USP. 2005;39(4):430-6.

9. Almeida VCF, Lopes MVO, Damasceno MMC. Teoria das relações interpessoais de Peplau: análise fundamentada em Barnum. Rev Esc Enferm USP. 2005;39(2):202-10. 